\title{
Preface to the Special Section of Selected Papers from the Australasian Conference on Data Mining (AusDM) 2016
}

\section{Kok-Leong Ong}

La Trobe Business School

La Trobe University

kok-leong.ong@latrobe.edu.au

\section{Zahid Islam}

School of Computing and Mathematics

Charles Sturt University

zislam@csu.edu.au

\section{Yanchang Zhao}

Data61

CSIRO

yanchang.zhao@csiro.au

This Special Section is a compilation of selected papers invited from Australasian Data Mining Conference (AusDM) 2016. The AusDM series began in 2002 as a Workshop and has grown each year since.

The conference is devoted to the art and science of data analytics and has in the recent years, heavily promoted the use of analytics in various business applications through an industry track reflecting the common goals and focus shared by the Australasian Journal of Information Systems.

It is therefore a privilege to have selected papers from AusDM 2016 to be included for publication at the Australasian Journal of Information Systems. Papers selected and invited from AusDM 2016 underwent a rigorous review process in line with the requirements of the journal. These papers include either new findings since the conference publication, or include additional content from the conference paper. The group of reviewers that have contributed to the reviewing of these publications are acknowledged below and as editors, we are deeply appreciative of their contributions to the process.

Of course, we wish to specially acknowledge the on-going support and patience of the Editor in Chief, Associate Professor John Lamp, whom we sincerely thank for accepting this Special Section proposal and the on-going support to make this happen.

- $\quad$ Lianhua Chi, IBM Australia

- $\quad$ Selvaraaju Murugesan, ACT Government

- Wei Peng, La Trobe University

- Wenyuan Li, University of Southern California

- Rana Ahmed, Alrafidain University College

- $\quad$ Yee-Ling Boo, RMIT University

- Jie Chen, University of South Australia

- $\quad$ Leminh Kieu, Data61, CSIRO

- Khondker Jahid Reza, Charles Sturt University

- Mouhib Alnoukari, Syrian Virtual University

- $\quad$ Ickjai Lee, James Cook University 
As we mentioned in the previous 2015 Special Section preface, the "need for organisations to make sense of their data has never changed". If anything, the ways in which we can now analyse data for various business applications and problems have evolved. And in 2017, this represents another maturing view of business analytics as well as a shift in focus within the research community in the last few years to concentrate more on how analytical outcomes can be used, evaluated and effectively communicated.

In some ways and on reflection, these questions might have been dismissed by hardcore computer scientist as problems in the realm of information system researchers. Within the emerging discipline of business analytics however, we are starting to see hardcore analytical methods and research increasingly overlapping with traditional problems or questions that were once considered by information systems researchers. This crossing of two disciplines is an exciting evolution that we are seeing and most likely, to take a bigger leap forward from 2018 and beyond.

The selected papers from the 2016 AusDM conference have reflected this with many developing solutions that draw and synthesize from multiple disciplines. We believe you will find the collection an interesting read and we hope you enjoy this Special Section.

Sincerely,

Ong, Islam and Zhao

Special Section Editors

Copyright: (C) 2017 Ong, Islam and Zhao. This is an open-access article distributed under the terms of the Creative Commons Attribution-NonCommercial 3.0 Australia License, which permits non-commercial use, distribution, and reproduction in any medium, provided the original author and AJIS are credited.

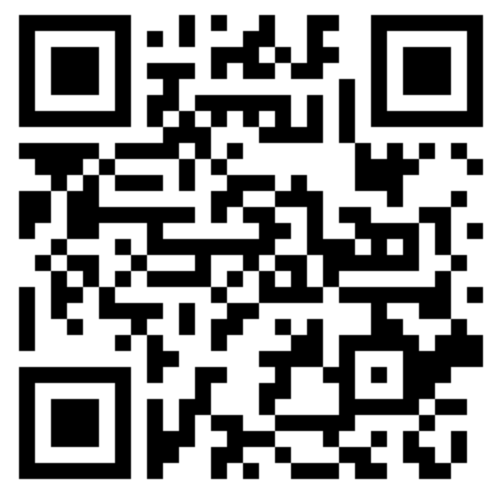

